\title{
STREAMING SERVICES FOR MUSICAL CONTENT DISTRIBUTION
}

\author{
Andreja Samčović \\ Svetlana Čičević
}

Faculty of Transport and Traffic Engineering, University of Belgrade,

Belgrade, Serbia
Correspondence:

Andreja Samčović

e-mail:

andrej@sf.bg.ac.rs

\begin{abstract}
:
This paper presents the prospective use of internet for the distribution of musical content to potential users. The main ways in which people gain access to musical content have undergone considerable shifts, exploiting the available technologies to allow opportunities for the reliable and secure distribution. Following the description of some musical streaming platforms, key elements of those systems are described, accompanied by their comparison.
\end{abstract}

Keywords:

streaming services, applications, musical content, internet.

\section{INTRODUCTION}

Until 130 years ago music could only be heard live from top orchestras and musicians, and only reach people could afford that satisfaction. The real revolution took place in 1877 when Thomas Edison invented a phonograph, a device that could record and reproduce the sound. Eleven years later, the first gramophone and gramophone record were created as the first carrier of sound. A new history in music started, and since then, music has become a true industry what is known today

The first audio cassette was developed by Philips in 1963. Since then audio cassettes have become very popular and used to record and reproduce the sound. The tape recorders were launched a little bit later, and the first commercial cassette recorder that came into use was produced in 1970. The first portable stereo device, a vocalist, was then created, with the development of pop and urban culture. Sony was the first company which produced a walkman in July 1979.

In the early eighties the musical recording and distribution switched to digital sound carriers and mega popular compact discs (CDs), and to mp3 (MPEG Layer 3) players in the nineties. Mp3 players were launched in 1998 in Germany. Since then, the digital era has the importance that is still on the road today. This is the field where the regulative and legislative standards and elements should be considered. Musicians and customers of their products are eager to distribute and play music whenever they wish, without any limitations of time and space. 
Nowadays, there is some nostalgic memory of the times when somehow slower music felt much deeper. As the technology progressed, the production of songs and audio recordings reached better quality. For instance, the first album in the world that used the QSound effect was Madonna's "The Immaculate Collection", after which all other artists recorded the music with such effect. QSound provided three-dimensional audio effects.

Our society is facing many changes in its modes of communication. The simultaneous emergence of mobile devices and online social networks allows the sharing of information from anywhere and with anybody. This opportunity enables people to overcome boundaries and expand their modes of communication. Today, in the 21st century, we do not have space or time either for musicians or for discs. We listen to the music via smart phones, Ipods or mp3 players. Sale of compact discs in musical stores has dropped significantly because internet downloading took a primate. All the singles and whole albums of the musical performers can be found and downloaded on the internet. With a couple of clicks, users can download entire albums of any performer without going to a CD shop.

Today, music streaming has become one of the best applications for the music distribution [1]. Pandora, Google Play Music, Apple Music, SoundCloud, Spotify are just some of the types of streaming music platforms that offer a great selection of songs, along with a number of additional features for a certain small amount of money. The music industry of the digital age has a great impact on musicians, both in the positive and in the negative sense. However, the music world has lots of oscillations in the internet environment [2]. Digital piracy and advertising rules on platforms like YouTube are the main sources of concern.

This paper is organized as follows: some basic aspects of internet streaming are described. The characteristics of several popular musical streaming platforms are presented in the next section, following by their comparison in terms of quality of streaming, supporting platforms, prices and features. Concluding remarks are discussed in the final part of the paper.

\section{STREAMING SERVICES APPLICATIONS}

Streaming is a technique for transmitting data over internet that allows processing as continuous uninterrupted string. For example, short video material of about $30 \mathrm{~s}$ can be watched immediately. The term streaming, in the context of the problem, describes the flow of information from server to a web site. In essence, streaming is a connection or pipeline between servers and client devices. The bandwidth of the connection determines how much information can be accessed into a player, where is important the bit rate. If too much information affect, they can overflow the player and the user will face to irregular reproduction. Therefore, one should keep in mind for digital videos that the bit rate controls the quality of reproduction [3].

Streaming media use the continuous data stream technique: sound and video that are reproduced immediately after being downloaded to the user system. By using these media the user minimizes the waiting time when downloading the file. Namely, media and multimedia files (audio, video, animations) are stored on streaming server in a special format. The user's search engine or directly included plug-in can begin to collect data before the whole file is transferred to the computer. In order the streaming to be successful, the user must be able to collect the data and pass them in a continuous stream to the applications that process them and turn into sound, animation or video.

\section{Streaming server}

Server is the main computer in the network, where the whole network, software and dedicated computer equipment are stored. That is a computer that provides software to other computers in network. Streaming server is intended for storing and sending media content for streaming over internet. The special RTSP (Real Time Streaming Protocol) protocol is used for the streaming service. In order to use streaming technology, two servers are required: a regular network server (web server) and an additional streaming server. Streaming server has a saved media file for streaming and then sends parts of that file in the continuous stream to the user. Streaming speed is adjusted depending on bandwidth of users' equipment.

Music streaming has started from the very beginning on the ascending path and has now become one of the best way for listen to the music. Many streaming services allow free listening to music, which helped to reduce the need for piracy [4]. The services are easily accessible and support many options. The best applications for musical streaming and download for the Android platform will be described in the following paragraphs. 


\section{Amazon Music}

Amazon Music is one of the most prized applications for musical streaming [5]. There are about a dozen millions of songs in the music catalog that can be bought and downloaded. Music can be downloaded on demand and anywhere on the platform, such as Google Play and Apple Music. In addition, prime membership can be used for other possibility related to the site, such as Prime Instant Video, a free two-day delivery (where possible) and much more, depending on the user's location. It's a solid option in general, and many users subscribe on this service, what makes this service basically free for these users. Use of this application at a monthly level costs $\$ 10.99$, and $\$ 99.99$ annually [6].

\section{Apple Music}

Apple Music exploded on the scene at the end of 2015 and has various criticisms, regarding several design features, like the lack of navigation bar titles at all in some views and incompatibility with all devices. However, it quickly became one of the best music streaming applications. There are 30 million songs, live 24/7, and music can be downloaded to the appropriate device. There are so-called social components within this application, which can follow a musician, and therefore his work. There are different subscriptions: individual at the monthly level for $\$ 9.99$, students' subscription with a $\$ 4.99$ discount and a family subscription, which includes six members with the amount $\$ 14.99$ per month. Accessibility in many countries is one of the most important features.

\section{Google Play Music}

Google Play Music is a streaming service that allows users to stream up to 50,000 of their own songs for free across most platforms, in addition to allowing free users to listen to curated stations and paid users to stream up to 40 million songs in their streaming library. It's an app with a lot of functions. Users also receive a YouTube Red membership with this application that allows watching videos without advertising on YouTube, listen music for free, but the list of songs is limited and tailored in the style of the radio. Users who pay have access to the entire list and additional features. The subscription for an individual is $\$ 9.99$ per month, while the family subscription, which includes six family members, is $\$ 14.99$.

\section{iHeartRadio}

iHeartRadio is a favorite for many users because it is completely free and contains very extensive content. This music service has over 1500 live radio stations that include various music genres. Also, there is a radio for live conversations, as well as a seasonal radio, for example Christmas music, and so on. Customized music stations can be created according to the user preferences, while the service can contain a catalog of 18 million songs of 450,000 artists. There is an individual track control, like Spotify or Google Play Music. Alongside with fairly limited interactivity, not allowing users to make their own playlists, as well as being dependent on quality of Internet connections, the use of this application is simple, like Pandora application. This is another music streaming service available on most platforms, as well as, on smart TV.

\section{Pandora}

Pandora is the most popular music streaming application. The Pandora environment is presented in Fig. 1. It can be found on every platform, including some vehicles, and it is user friendly. Popularity of this service jumped very fast. Users can download a certain number of music tracks for free, while the users who subscript have no restrictions. The price for monthly usage is $\$ 9.99$. The problem is that the catalog includes around a million songs. However, most users do not feel that problem. On the contrary, Pandora is able to offer the best curated, radio-style streaming online due to its Music Genome Project capturing the abundance of data about each song based on simple thumbs up or thumbs down ratings. Pandora Premium was launched at the beginning of 2017, and can be compared to the Apple Music and Spotify applications.
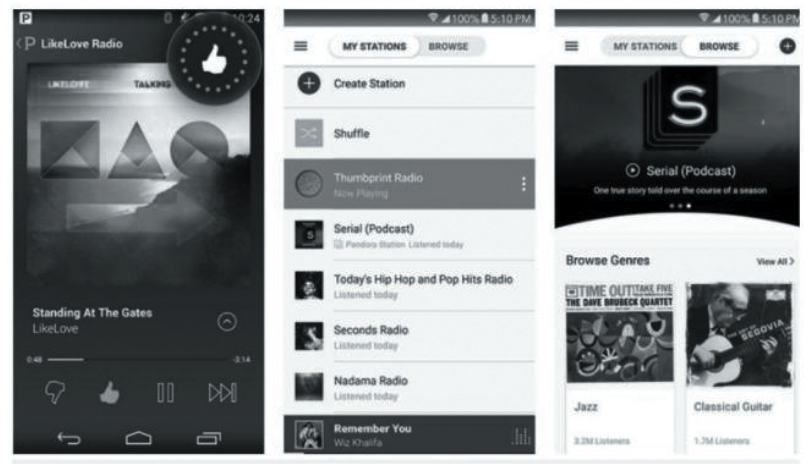

Fig. 1. Pandora aplication [7] 


\section{Slack Radio}

Slack Radio is underestimated in the domain of applications for music reproduction, but it's actually pretty good. The free version is similar to Pandora with limited use for six hours, as well as, with the feature of creating new radio stations. The price of $\$ 3.99$ per month provides free listening, unlimited number of songs and offline stations. The Slack Radio environment is shown in Fig. 2. Users who are subscripted receive a playlist on demand as Spotify, as well as hand-made list. There are 12 million songs, about a third of those stored by Apple Music, Spotify and Google Play Music.

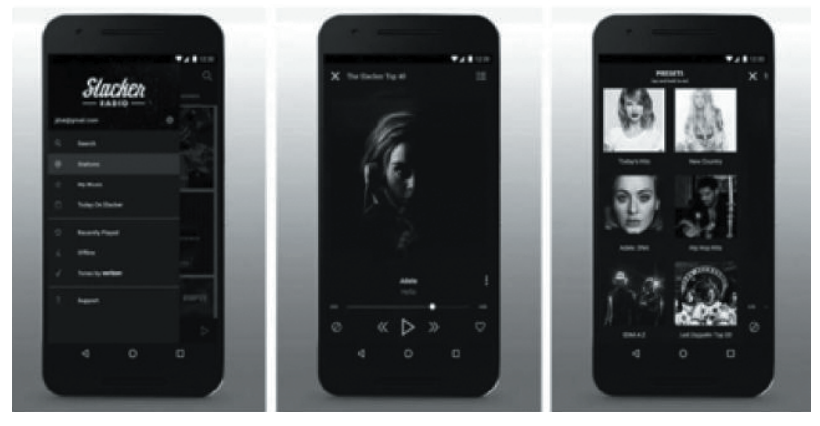

Fig. 2. Slack Radio environment [7]

\section{SoundCloud}

The environment of the SoundCloud application is shown in Fig. 3. It belongs to the one of the funniest applications for music streaming. SoundCloud's biggest asset is its extremely creative, massive user base (nearly 200 million active users per month). It was an independent medium for the years. SoundCloud Go was launched at the beginning of 2016, which included everything as SoundCloud, together with popular music of famous musicians. Also, it is possible to find 125 million songs on the SoundCloud platform. The solid full service is included in this service. There will be no library of the musicians for free. Price for an individual on a monthly basis is $\$ 9.99$.
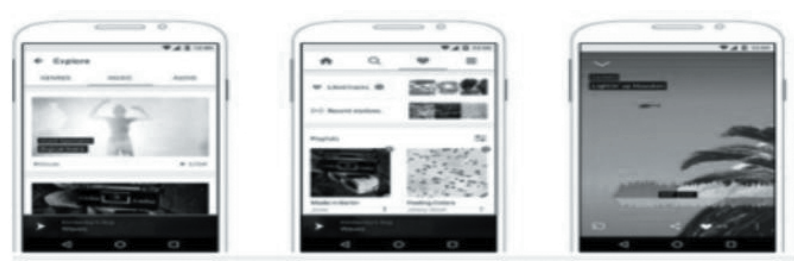

Fig. 3. SoundCloud environment [8]
Spotify

Spotify (whose environment is shown in Fig. 4) is the most important application for streaming music, at least now. This service was launched 2008 in Great Britain, Germany, France, Italy, Spain, Finland and Norway. The name of this application consists of two words, i.e. a spot that means a site and identify, which means identification. Spotify has over 30 million songs in the library, a play list, research tools and video content. Its popularity is owing to extremely user-friendly and hassle-free interface on desktop, iOS, and Android and numerous third-party integrations, such as Amazon's Alexa and Google Cast. Spotify can be used for free, with an access to playlists, but full subscription must be paid to use the entire application. There is family subscription, as for the Apple Music and Google Play Music, which is $\$ 14.99$ for six people in family. For individuals on a monthly basis, the subscription is $\$ 9.99$. There are also discounts for students.

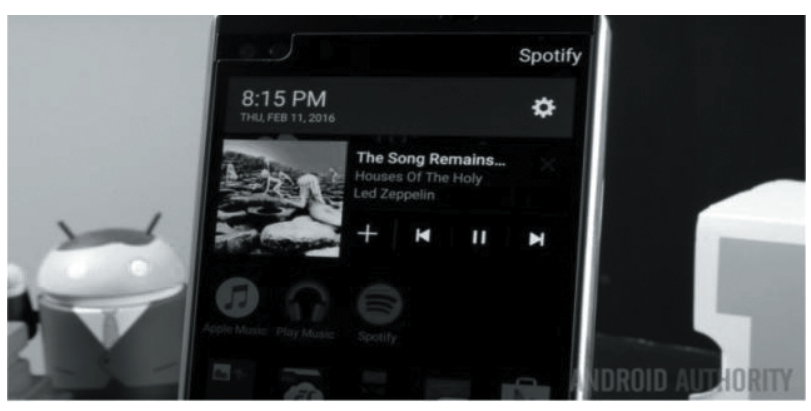

Fig. 4. Spotify environment [8]

TIDAL

$T I D A L$ is an interesting streaming service. It is claimed that it has the highest number of membership fees and that it can boast a catalog of 25 million songs along with 130,000 music video clips. The application had some problems in the past, but they are now improved. Regular music streaming has maximum $320 \mathrm{~kb} / \mathrm{s}$ (kilobits per second), which can be paid for $\$ 19.99$. There is also a subscription of $\$ 9.99$ per user on a monthly basis. The options like music history articles, offline fashion and other options are available with this application. It is a perfect audio file that can not contain large FLAC (Free Lossless Audio Codec) melody collections on a device. It is proper for those with highquality gear who care more about the fidelity of their audio source than interface usability or library size. The environment of this application is illustrated in Fig. 5. 

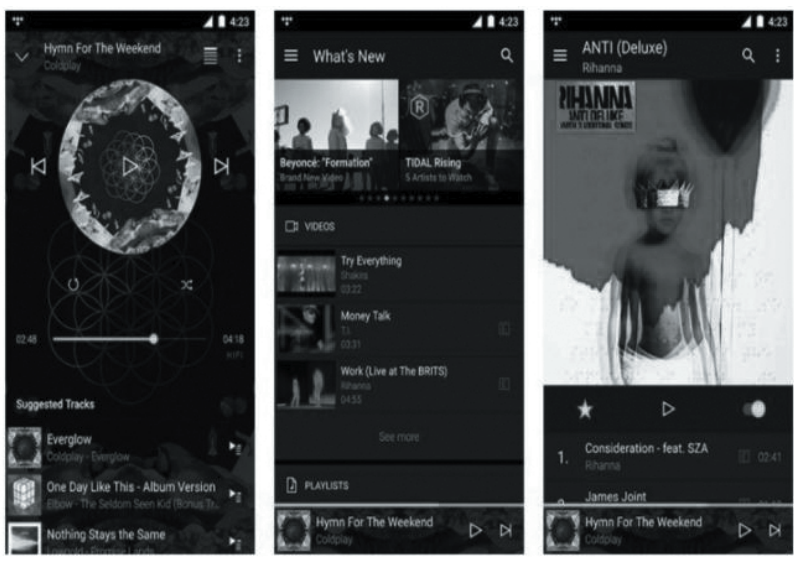

Fig. 5. TIDAL environment [8]

Tunnel

Tunnel is not the most important music streaming application, but there's plenty to offer, similar to services like radio stations. How the Tunnel environment looks like is shown in Fig. 6. Over 100,000 radio stations are in the offer that includes music, speech, comedy, sports and other types of radio stations. There are AM and FM stations. With the subscription of $\$ 7.99$ per month, there is access to 600 music stations without commercial content, advertisements and additional spots. It is a great option as a whole, giving possibility for users with different interests.
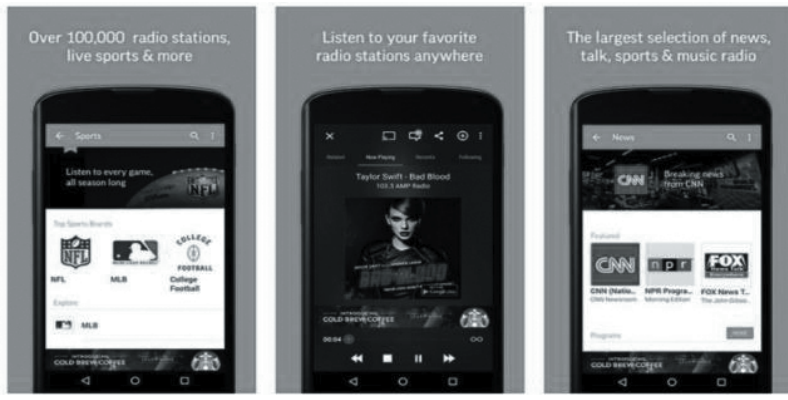

Fig. 6. Tuneln environment [7]

Fig. 7 shows the most used music services in 2017, compared with their prices and several features, like editor's rating, sound quality, availability of free version, live programming and similar.

\section{Deezer music}

Deezer music is a music service which can be downloaded over mobile phone, tablet or laptop. This service can be used via wireless internet or offline mode, even without connection to the internet. There is a large selection of thematic radio stations that Deezer music makes available. All what should be done is to choose a favorite musician or genre and to enjoy unlimited music, anytime and anywhere. Deezer music is offered by Telenor mobile operator. Deezer service is available for all users (individuals) through Moj Telenor application or the portal and is valid for 30 days from the day of activation. Activation of Deezer service as a tariff supplement is charged in the amount of 495 RSD with tax. If users opt for a specific package where is Deezer as a service that can be used, then it is not charged within the package. The activated plug-in is automatically updated every month. The user can unsubscribe from the service in any time via an application or a portal.

\section{YouTube Red}

Google's platform YouTube for sharing of multimedia content offers the first premium subscriber music video service on all platforms for ten dollars per month. Apple premium services are charged 30\% higher than the others. YouTube Red service allows the following:

- Unlimited listening and watching videos/music without commercials;

- Video downloading to the phone or computer;

- Listen to YouTube content in the background (while working in other applications);

- Free access to the Google Play Music service (and vice versa);

- Watch special movies and series only for YouTube Red users.

\section{MUSIC APPLICATIONS IN SERBIA}

The basic problem that stopped the serious spread of music streaming services in Serbia was the quality of mobile networks of national operators. Now, when this obstacle is at last overcome and network is upgraded, with the introduction of $4 \mathrm{G}$ network in the main city centers, the gate to expand these services seems to be completely open. While most of the developed world has been using Spotify or Google Play Music, the first authentic offer in this field in our country is Deezer. 
Available primarily to Telenor users through individual postpaid packages, or as a tariff supplement, Deezer offers in principle everything as the Spotify, with an appropriate catalog of local performers.

The users of iOS devices in Serbia also have the possibility to use Apple Music service. It can be said that this service is legally available, since Apple's App Store for Serbia is definitely launched. Since the official launch of $i$ Phones, operators have been providing users to be registered in the United States.

Although Spotify and Google Play Music are not officially available in Serbia, the enthusiasts overcome this problem by using some of the VPN (Virtual Private Network) applications. On the other hand, Spotify's subscription, activated for example, during a stay in some of the European countries, works perfectly in our country.

Perhaps the most important part of the music streaming service is the aspect of new music intelligence, i.e. proposing songs of similar authors and bands based on user habits and music collections already transferred to the device. The vast majority of the first reviews agree that Apple's service is currently perhaps the closest to the ideal in this respect. Table I illustrates the comparison of some important music streaming services.

\begin{tabular}{|c|c|c|c|c|c|c|c|c|c|c|}
\hline Name & $\begin{array}{c}\text { SiriusXM } \\
\text { Internet } \\
\text { Radio }\end{array}$ & $\begin{array}{c}\text { Slacker } \\
\text { Radio }\end{array}$ & $\begin{array}{l}\text { Amazon } \\
\text { Music Un- } \\
\text { limited }\end{array}$ & Spotify & Tidal & $\begin{array}{l}\text { Apple } \\
\text { Music }\end{array}$ & $\begin{array}{c}\text { Google } \\
\text { Play } \\
\text { Music }\end{array}$ & $\begin{array}{c}\text { Microsoft } \\
\text { Groove } \\
\text { Music }\end{array}$ & $\begin{array}{l}\text { iHeart } \\
\text { Radio }\end{array}$ & $\begin{array}{c}\text { Pandora } \\
\text { Internet } \\
\text { Radio }\end{array}$ \\
\hline & 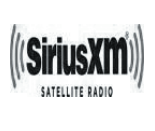 & Slackel & $\underbrace{\text { music }}$ & 太ิspotify & $\stackrel{*}{*}$ & inusc & 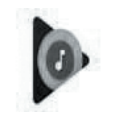 & (0) Microsoft & $\begin{array}{l}((0)) \\
\text { iHeart } \\
\text { RADIO }\end{array}$ & $\underbrace{\mathbf{P}}_{\text {PANDORA }}$ \\
\hline $\begin{array}{c}\text { Lowest } \\
\text { price }[\$]\end{array}$ & 10.99 & 9.99 & 9.99 & 9.99 & 9.99 & 9.99 & 9.99 & 9.99 & 4.99 & 4.99 \\
\hline $\begin{array}{c}\text { Best sound } \\
\text { quality } \\
{[\mathrm{kb} / \mathrm{s}]}\end{array}$ & 320 & 320 & 256 & 320 & 1411 & 256 & 320 & 192 & 128 & 192 \\
\hline $\begin{array}{c}\text { Free ver- } \\
\text { sion avail- } \\
\text { able }\end{array}$ & $\mathrm{X}$ & + & $\mathrm{X}$ & + & $\mathrm{X}$ & $\mathrm{X}$ & + & $\mathrm{X}$ & + & + \\
\hline $\begin{array}{c}\text { Mobile } \\
\text { app }\end{array}$ & + & + & + & + & + & + & + & + & + & + \\
\hline $\begin{array}{l}\text { Live } \\
\text { program- } \\
\text { ming }\end{array}$ & + & + & $\mathrm{X}$ & $\mathrm{X}$ & $\mathrm{X}$ & + & $\mathrm{X}$ & $\mathrm{X}$ & $\mathrm{X}$ & $\mathrm{X}$ \\
\hline $\begin{array}{l}\text { Non-mu- } \\
\text { sic content }\end{array}$ & + & + & + & + & + & + & + & + & + & + \\
\hline $\begin{array}{l}\text { Song } \\
\text { lyrics }\end{array}$ & $\mathrm{X}$ & $X$ & + & $\mathrm{X}$ & $\mathrm{X}$ & + & $\mathrm{X}$ & + & $\mathrm{X}$ & + \\
\hline
\end{tabular}

Table 1. Comparison of most used music streaming services

\section{PERFORMANCES OF SOME MUSIC STREAMING APPLICATIONS}

Naturally, by entering of Apple into the streaming music market, the race between services has been sharply strengthened. The other big players in this market are trying to further improve their offer. Most users of
Apple's application are converting from other services, largely from Spotify - with a lot of users for whom Apple Music is the first service. Spotify is, according to the scope of the offered catalog, practically equal to the newly-established Apple service (Deezer and Google are also comparable, as can be seen in Table II). However, the so-called music discovery part of the offer is 
evidently weaker. The latest version of Spotify application is published, trying to improve the situation in this field. It remains to be seen how much this specification will succeed. As for Deezer, judging by user reactions from various surveys that can be found online, the quality of the offer in this field is somewhere halfway between Spotify and Apple Music.

This does not mean here the radio in the classical sense. It is about the option of creating the own mix, i.e. thematic radio stations based on the songs of the selected band, along with the selection of genre-like authors selected by the machine itself. All the leading music streaming services have this option in some form, customizing algorithms to better respond to user requirements. It is currently one of the most important fronts for a share in the user base.

As the boundaries between "old" and "new" music services and applications fade and overlap, it is increasingly perceived as a place where one service can be highlighted. Musical editors create playlists and recommend novelties, and as part of its service, Apple has launched "live" radio station Beats 1, which broadcasts 24 hours a program. Unfortunately, VPN will be required to listen to Beats 1 in Serbia.

Each of these services has an attention to connect users, and we come to some important details. We effectively stop buying music by switching to streaming. According to DRM (Digital Rights Management) conditions, files do not belong to users, even when they are transferred to the device for off-line listening. Files can be used as long as the user is subscribed to a given service. We entered into the era of music renting, and that is why details about the streaming service are important such as the volume of the catalog and the quality of broadcast sound. Leading services will certainly be separated with the engagement of prominent authors who would publish exclusive content on their platforms [9].

The quality of the streaming is a special topic, although the leading services have a high quality bit rate $(320 \mathrm{~kb} / \mathrm{s}$ or equivalent, at least for premium users, Table II). However, since 2014 and especially since the first half of 2015, the largest markets have integrated audio streaming service data into the official top singles and albums list. In addition to music streaming applications that try to replace the embedded music player with the user's smart phone, another important application tries to replace old radio, and to improve this experience. Mixcloud is by far the most popular application among these services, especially after the Grooveshark closure. It is distinguished by a huge number of programs and authors who set their own programs/mixes, whether it is broadcast content on classical radio stations or exclusively streaming programs [10].

\begin{tabular}{|c|c|c|c|}
\hline & $\begin{array}{l}\text { Quality of } \\
\text { streaming }\end{array}$ & Catalog size & $\begin{array}{c}\text { Supported } \\
\text { mobile } \\
\text { platforms }\end{array}$ \\
\hline Spotify & $\begin{array}{l}320 \mathrm{~kb} / \mathrm{s} \text { Vorbis } \\
\text { for } \\
\text { Premium users; } \\
160 \mathrm{~kb} / \mathrm{s} \text { Vorbis } \\
\text { for free usage with } \\
\text { commercials }\end{array}$ & $\begin{array}{l}\text { More than } \\
30 \text { millions }\end{array}$ & $\begin{array}{c}\text { Android } \\
\text { iOS } \\
\text { Windows } \\
\text { Phone }\end{array}$ \\
\hline Deezer & $\begin{array}{c}320 \mathrm{~kb} / \mathrm{s} \\
(\text { Premium }+) \\
\text { or } 128 \mathrm{~kb} / \mathrm{s} \mathrm{mp} 3 \\
\text { (free, with com- } \\
\text { mercials) }\end{array}$ & 35 millions & $\begin{array}{l}\text { Android } \\
\text { iOS } \\
\text { Windows } \\
\text { Phone }\end{array}$ \\
\hline $\begin{array}{l}\text { Google } \\
\text { Play } \\
\text { Music }\end{array}$ & $\begin{array}{c}320 \mathrm{~kb} / \mathrm{s} \mathrm{MP3} \\
\text { (with adjusting } \\
\text { to the quality of } \\
\text { internet } \\
\text { connection) - free, } \\
\text { with commercials }\end{array}$ & $\begin{array}{l}\text { More than } \\
30 \text { millions }\end{array}$ & $\begin{array}{c}\text { Android } \\
\text { iOS }\end{array}$ \\
\hline $\begin{array}{l}\text { Apple } \\
\text { Music }\end{array}$ & $\begin{array}{c}256 \mathrm{~kb} / \mathrm{s} \mathrm{AA} \\
\text { (equivalent to } \\
\text { iTunes } \\
\text { Plus); depends on } \\
\text { streaming } \\
\text { over } \text { wi-fi or } \\
\text { mobile network }\end{array}$ & 30 millions & $\begin{array}{c}\text { Android } \\
\text { iOS }\end{array}$ \\
\hline
\end{tabular}

Table 2. Quality of streaming, catalog size and supported mobile platforms for music applications

The lack of built-in applications with a comprehensive list of streams of internet radio stations, such as the desktop version of iTunes, is compensated by Tuneln Radio, available for both the leading mobile platforms (and even for Windows Phone). The application also offers a choice of quality streams for radio stations that support (and the memory of that choice), which makes it possible to find an adequate compromise between the amount of data consumed and the sound quality. The majority of the radio stations give a playlist of broadcast songs and program overview. In 2014, earnings from downloading and streaming music globally exceed for the first time the profit from the sale of physical formats, i.e. CDs. Although the download of digital format still prevails with $52 \%$, streaming services record a serious growth. One of the most serious players in the field of digital music, Apple, has just seriously entered on audio streaming market. 


\section{CONCLUSION}

The music industry has used a variety of listening formats over the past 25 years. Different digital formats appeared for consumers. The transition to digital formats made the music industry more complex. Various forms of digital transmission and broadcasts continue to grow even today. There have never been so many ways to listen to music online as are present now. There are services for downloading and listening to the music over social networks, streaming services and smart phone applications. The advantage of distributing music over streaming involves branding, cultural democracy, social inclusion, education, and even the dignity of people.

\section{ACKNOWLEDGMENT}

This paper is partially supported by the Ministry of Education, Science and Technological Development of the Republic of Serbia (Projects No. 32025, 32048, 36022, and 36006).

\section{REFERENCES}

[1] M. Marković, Audio-vizuelna pismenost, Univerzitet Singidunum, Beograd, 2008.

[2] A. Gamel, The evolution of the music industry in the post-internet era, CMC Senior Theses, Paper 532, 2012.

[3] A. Samčović, Multimedijalne komunikacije, Univerzitet u Beogradu - Saobraćajni fakultet, Beograd, 2015.

[4] E.W. Pittman, Are music streaming services healthy for the recorded music industry?, BSc thesis, University of Arkansas, USA, 2016.

[5] T. Nikolaus, S. Florian, L. Patrick, and B. Patrick, "Technological and consumer shifts in the music industry," Journal of Case Studies, Vol. 35, No. 1, pp. 73-90, May 2017.

[6] K. Calvert, Profitability in the digital age music industry, IU School of Public and Environmental Affairs, 2013.

[7] "The best online music streaming services of 2017." Internet: https:/www.pcmag.com/article2/0,2817,2380776,00

[8] "10 best music streaming apps and music streaming services for Android.” Internet: http://www.androidauthority.com/best-music-streaming-apps-for-android-213818

[9] J. Sahlman, Digital music distribution channels for independent bands, Master thesis, Laurea University of Applied Sciences, Finland, January 2014.

[10] P. Kabanda, Music for development in the digital age, World Development Report, March 2016. 